\title{
PENGENDALIAN JARINGAN DISTRIBUSI 20 KV DENGAN MENGGUNAKAN SISTEM SCADA
}

\author{
Isworo Pujotomo \\ Teknik Elektro, Sekolah Tinggi Teknik - PLN \\ isworop@yahoo.com
}

\begin{abstract}
In Indonesia, especially at PT PLN (Persero), SCADA has been known and started to be implemented in the control of electric power systems since the early 1980s in many other countries that are more advanced, SCADA application is growing in line with the development of computer technology and telecommunications.

By the time the development is not as sophisticated SCADA now, there are thought to facilitate maneuvers on a system that is simple to use SCADA network we can supply additional power or power outage easily do so overloaded that did not happen.

After implementing a SCADA system occurred saving time for 2906 minutes or 48.44 hours, and the frequency of outages 4 times less than that before implementing the SCADA system. This means that the reliability index SAIDI and SAIFI much better at the moment after the implementation of the SCADA system.
\end{abstract}

Keywords : SCADA, SAIDI, SAIFI,implement

Abstrak : Di Indonesia khususnya di PT.PLN (Persero), SCADA telah dikenal dan mulai diimplementasikan dalam pengendalian sistem tenaga listrik sejak awal tahun 1980. Di berbagai negara lain yang sudah lebih maju, penerapan SCADA semakin berkembang seiring dengan perkembangan teknologi komputer dan telekomunikasi.

Pada saat perkembangan SCADA belum secanggih sekarang, ada pemikiran untuk mempermudah manuver yaitu pada sistem jaringan sederhana dengan menggunakan SCADA kita dapat menyuplai daya tambahan atau melakukan pemadaman listrik dengan mudah agar kelebihan beban tersebut tidak terjadi.

Setelah mengimplementasikan sistem SCADA terjadi penghematan waktu sebesar 2906 menit atau 48,44 jam, dan frekuensi padamnya 4 kali lebih sedikit dibandingkan dengan sebelum mengimplementasikan sistem SCADA. Ini artinya indeks keandalan SAIDI dan SAIFI jauh lebih baik pada saat setelah mengimplementasikan sistem SCADA.

Kata kunci : SCADA, SAIDI, SAIFI, implementasi

\section{PENDAHULUAN}

Sistem distribusi tenaga listrik meliputi semua jaringan tegangan menengah $20 \mathrm{kV}$ dan semua jaringan tegangan rendah 220/380 V hingga meter-meter pelanggan. Distribusi tenaga listrik dilakukan dengan menarik kawat-kawat distribusi baik pengantar udara maupun pengantar di bawah tanah dari mulai gardu induk hingga kepusat-pusat beban.

Sejalan dengan perkembangan teknologi, di mana ketergantungan terhadap tenaga listrik semakin tinggi sedangkan dipihak lain tersedia sumber daya alam yang semakin menipis, dibarengi pula dengan semakin kritisnya pencinta alam terhadap kelestarian dan kebersihan lingkungan, maka penelitian dan pengembangan baru dalam bidang kelistrikan dan elektronika, terutama dalam dekade terakhir ini, cukup pesat. Salah satu diantaranya adalah dalam bidang pengelolaan sistem tenaga listrik mulai dari pembangkitan, transmisi, distribusi hingga pelayanan pelanggan, yang utamanya ditunjukkan untuk memperoleh pengelolaan sistem yang aman, dengan mutu yang baik, tetapi dengan biaya yang efisien.

Sistem pengaturan tersebut berkembang mulai dari sistem pengaturan 
konvensional dimana tiap-tiap sub-sistem (seperti gardu induk) memerlukan operator, disusul kemudian dengan sistem pengaturan berbasis komputer agar sistem konvensional tersebut dapat dipantau dan diawasi secara terpusat dari jarak jauh, dan yang terakhir adalah sistem pengaturan secara terintegrasi dimana sub-sistem tidak memerlukan operator lagi, yang berarti fungsi operator diambil alih sepenuhnya oleh pusat kontrol operator.

\section{LANDASAN TEORI}

\subsection{Tipe-Tipe Jaringan Distribusi Tegangan Menengah $20 \mathrm{KV}$}

\section{Radial}

Jaringan radial adalah bentuk jaringan yang paling sederhana yang menghubungkan beban dengan sumber.

Sifat sistem ini : biaya murah, tidak ada alternatif pasokan, keandalan rendah, pengaturan tegangan dapat dilaksanakan dengan baik.

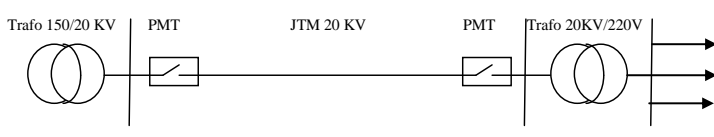

Gambar 1. Jaringan Distribusi

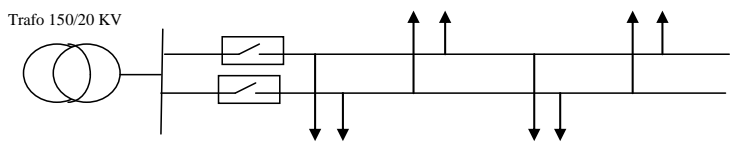

Gambar 2. Jaringan Distribusi Tipe Radial

\section{Sistem Spindle}

Sistem Spindle merupakan salah satu struktur untuk meningkatkan keandalan dengan membuat semua penyulang yang keluar dari Gardu Induk menuju kesatu titik pertemuan sehingga membentuk suatu lingkaran yang terbuka, pada titik pertemuan tersebut yang disebut titik refleksi. Titik refleksi ini dalam praktek merupakan Gardu-Hubung (GH) atau switching substation.

Struktur spindle ini selalu disediakan penyulang cadangan khusus yang lebih dikenal dengan sebutan penyulang ekspres. Penyulang ekspres ini tidak mencatu gardu-gardu distribusi, tetapi merupakan penyulang penghubung antara Gardu Induk dengan Gardu Hubung yang dimaksudkan untuk menjaga kelangsungan pemasokan tenaga listrik pada pelanggan-pelanggan, bila terjadi gangguan pada suatu penyulang yang memasok gardu-gardu distribusi.

Luas penampang kabel dari setiap penyulang, baik yang mencatu gardugardu distribusi maupun penyulang ekspres sama besarnya.

Bila kemampuan nominal dari satu penyulang sama dengan $\mathrm{P}, \mathrm{n}$ adalah banyaknya penyulangnya, maka jumlah penyulang yang akan mencatu gardugardu distribusi adalah ( $\mathrm{n}-1)$, dan batas kemampuan yang diperbolehkan dari penyulang ini adalah:

$$
\frac{(n-1) P}{n}
$$

dimana $\frac{(n-1)}{n}$ disebut koefisien penggunaan.

Berdasarkan pengalaman, banyaknya penyulang dalam suatu spindle adalah 7 buah penyulang. Pada keadaan seperti ini koefisien penggunaannya adalah $6 / 7$ atau $85,6 \%$.

Dan sistem spindle ini adalah tipe jaringan distribusi yang dipakai pada jaringan distribusi $20 \mathrm{KV}$ oleh PT. PLN (Persero) Distribusi Jakarta Raya dan Tangerang.

\section{Struktur Gelang}

Struktur Gelang atau juga disebut Ring atau Loop, merupakan sistem yang memiliki keandalan lebih baik dari pada sistem Radial, jaringan mendapat catu listrik dari kedua ujungnya. Apabila terjadi gangguan di sutau tempat, maka PMT di Gl akan membuka dan membuat seluruh daerah padam. Setelah dilokalisir gangguannya, GI bisa dihidupkan kembali sampai ke daerah titik gangguan tersebut. Sisanya disuplai oleh penyulang lainnya. Untuk menjaga keandalan, biasanya dibuat terbuka (open loop), sehingga daerah yang padam pada saat gangguan tidak terlalu banyak.

\section{Sistem Anyaman}

Jaringan anyaman / mesh / grid merupakan jaringan yang strukturnya 
komplek, dimana kelangsungan penyaluran dan kualitas pelayanan sangat diutamakan. Struktur anyaman ini umumnya dipakai pada jaringan tegangan rendah yang kepadatan bebannya cukup tinggi.

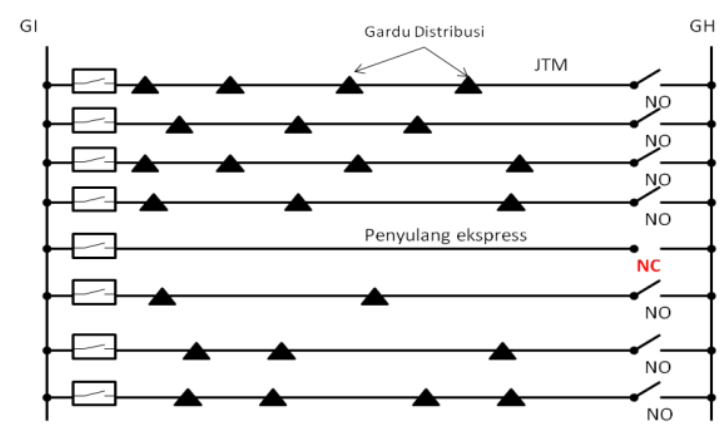

Gambar 3. Jaringan Sistem Spindle
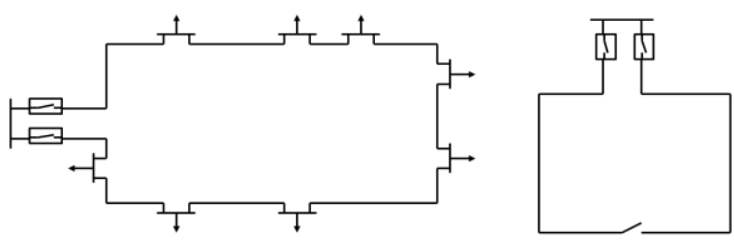

Gambar 4. Struktur Gelang Tertutup (close loop)

Gambar 5. Struktur Gelang Terbuka (open loop)

Keterangan :

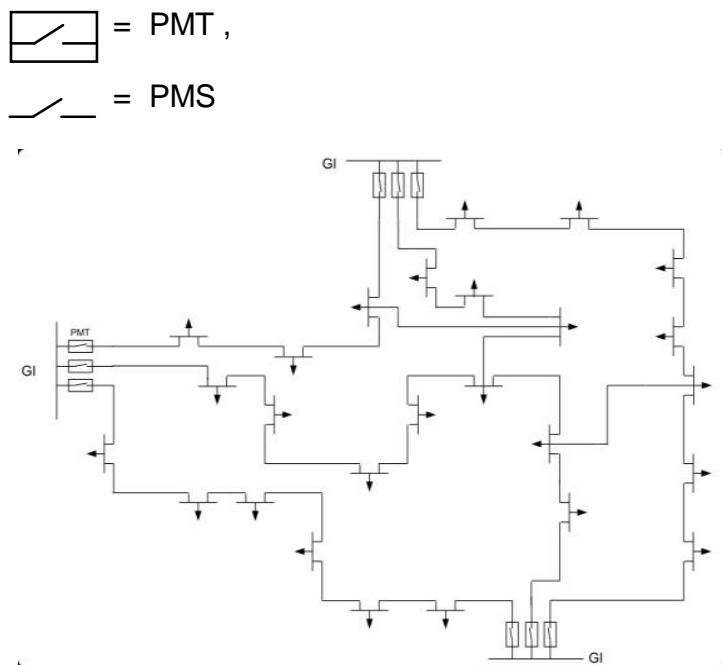

Gambar 6. Jaringan Distribusi Sistem Anyaman

\subsection{SISTEM SCADA}

Sistem adalah kumpulan dari beberapa alat atau komponen yang membentuk suatu kesatuan dan bekerja bersama-sama. Sedangkan SCADA merupakan singkatan dari Supervisory Control And Data Acquisition.
- $\quad$ Supervisory = Pengawasan

- Control = Kontrol

- Data Acquisition =

Permintaan/Pengiriman Data

Jadi, sistem SCADA adalah suatu kesatuan dari beberapa peralatan yang saling berkomunikasi untuk menjalankan fungsi pengawasan, pengontrolan, dan pengumpulan data dari suatu proses.

Prinsip dasar Sistem SCADA ada 2, yaitu :

1. Memantau dan mengontrol semua peralatan yang terdapat pada suatu sistem dari jarak jauh.

2. SCADA bekerja mengumpulkan informasi, kemudian mentransfemya ke sentral dengan membawa datadata dan sinyal kontrol (status) yang kemudian diperagakan pada sejumlah layar operator.

SCADA merupakan suatu sistem untuk pengendalian dan pemantauan jarak jauh. Dalam sistem tenaga listrik SCADA bertujuan untuk membantu mendapatkan sistem pengoperasian yang optimum.

Pada umumnya proses pengendalian pada sistem tenaga listrik jarak jauh terdiri atas 4 macam, yaitu :

1. Pengendalian buka/tutup perangkat pemutus daya, pemisah serta start/stop dari generator.

2. Pengendalian perangkat-perangkat regulator seperti pengaturan set point atau menaikkan dan menurunkan posisi tap changer.

3. Pemantau dan pengaturan beban.

4. Pengendalian yang dilakukan secara otomatis untuk keseragaman dan pengendalian perintah berurutan, misalnya merubah konfigurasi jaringan.

\subsubsection{Proses Pengendalian Dengan Sistem SCADA}

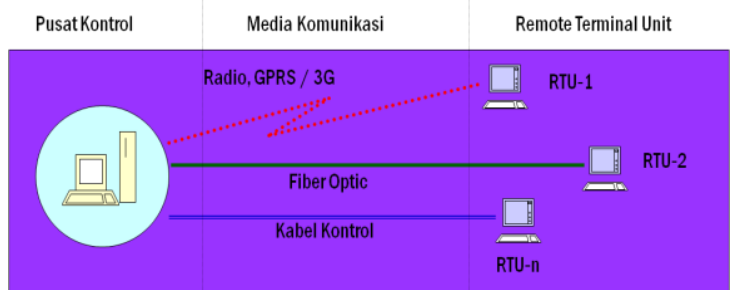

Gambar 7. Proses Pengendalian Dengan Sistem Scada 
Sistem SCADA dapat difungsikan dari pusat kontrol melalui komputer utama (main computer). Dari tampilan pada layar komputer utama inilah dispatcher dapat melakukan pengawasan dan pengendalian terhadap jaringan listrik, khususnya jaringan distribusi bagi PT. PLN (Persero) Distribusi Jakarta Raya dan Tangerang. Pada saat dispatcher melakukan suatu perintah maka komputer utama mengirimkan sinyal ke remote terminal unit (RTU) melalui media komunikasi. Apabila media komunikasinya tidak baik, maka sinyal yang dikirimkan tersebut tidak akan sampai diterima oleh RTU, untuk itu dibutuhkan media komunikasi yang cukup handal agar sinyal yang dikirim dapat diterima oleh RTU dalam waktu yang singkat sehingga dapat terlaksana sebagaimana mestinya. Setelah RTU menerima sinyal dari komputer utama, maka RTU akan melakukan suatu perintah berdasarkan sinyal yang dikirim tersebut, seperti perintah membuka atau menutup PMT (Pemutus Tenaga) / PMS (Pemisah Tenaga) / LBS (Load Break Switch). Setelah RTU melaksanakan perintah, maka RTU akan memberi tahu kepada dispatcher bahwa perintah tesebut telah dilaksanakan, yaitu dengan mengirimkan sinyal kembali komputer utama melalui media komunikasi sehingga terbacalah status PMT / PMS / LBS dalam keadaan terbuka atau tertutup.

Pusat kontrol (Master Station) merupakan komputer utama (Server). Komputer utama biasanya berjumlah 2 buah. Hal ini dimaksudkan untuk membentuk dual sistem (Master/Slave) sehingga sistem tidak bergantung hanya pada 1 komputer utama saja. Hal ini dimungkinkan karena jika terjadi gangguan pada komputer utama (Master), aplikasi komputer Master secara otomatis akan stop, dan komputer Slave secara otomatis akan menggantikannya sebagai Master sehingga availibilitas sistem secara keseluruhan lebih terjamin.

Fungsi dari komputer utama adalah untuk:

a. Mengatur komunikasi antara dirinya sendiri dengan RTU.

b. Mengirim dan merima data dari RTU kemudian menterjemahkannya kedalam bentuk informasi yang dapat dimengerti oleh user.

Mendistribusikan informasi tersebut ke MMI (Main Machine Interface), Mimic Board dan Printer Logger dan mem-file informasi tersebut.

\subsubsection{Media Komunikasi}

Media komunikasi adalah salah satu bagian terpenting yang tidak dapat dipisahkan dari suatu sistem pengendalian tenaga listrik, yaitu suatu subsistem yang merupakan sarana telekomunikasi yang digunakan untuk menghubungkan perangkat-perangkat sistem pengendalian khususnya antara master stasion dengan perangkat-perangkat remote terminal unit.

Ada beberapa media komunikasi yang digunakan untuk komunikasi data komputer utama di pusat kontrol dengan RTU yang dipasang di gardu-gardu listrik PLN, antara lain :

a. Kabel Kontrol

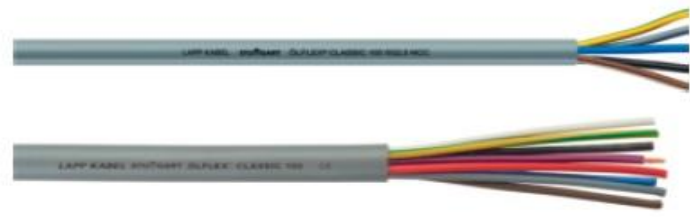

Gambar 8. Kabel Kontrol

b. Fiber Optik

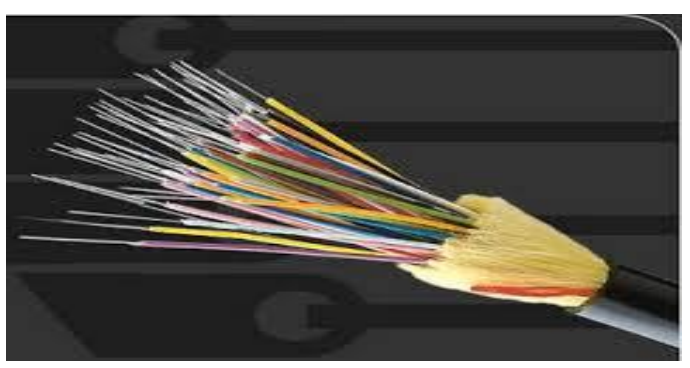

Gambar 9. Fiber Optik

c. Radio

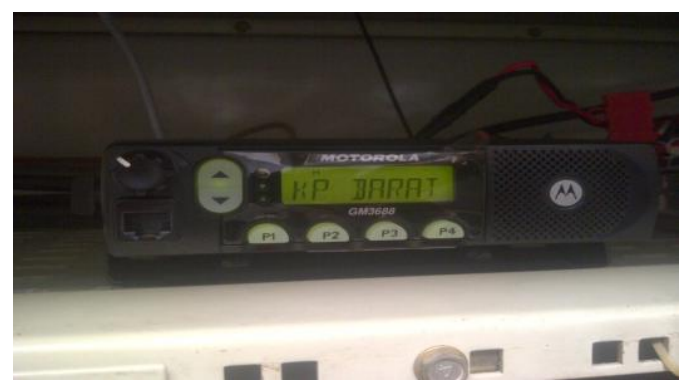

Gambar 10. Radio Voice 


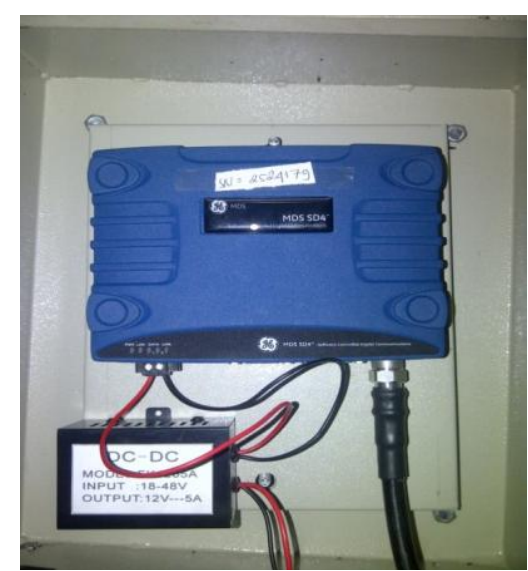

Gambar 11. Radio MDS

d. GPRS / 3G

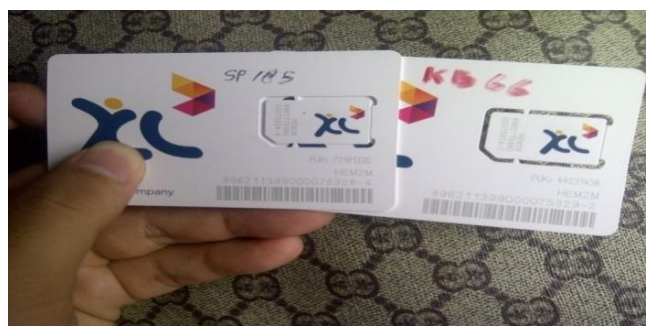

Gambar 12. SIM Card GPRS / $3 G$

\subsubsection{Remote Terminal Unit (RTU)}

Remote Terminal Unit adalah salah satu komponen dari suatu sistem pengendalian tenaga listrik yang merupakan perangkat elektronik yang dapat diklasifikasikan sebagai perangkat pintar. Biasanya ditempatkan di gardu-gardu maupun pusat-pusat pembangkit sebagai perangkat yang diperlukan oleh pusat kontrol untuk mengakuisisi data-data rangkaian proses untuk melakukan remote control, teleindikasi dan telemetering. Perangkat ini merupakan alat pendengar, melihat dan sebagai tangan dari pusat pengendalian.

Agar semua kejadian yang terjadi di gardu PLN, baik Gardu Induk, Gardu Hubung, dan Gardu Distribusi dapat dipantau dan dikontrol dari Pusat Kontrol, maka di setiap gardu tersebut harus dipasang RTU yang dapat melaksanakan fungsi Tele Status (TS), Remote Control (RC) dan Tele Meter (TM). RTU sebenarnya sama saja dengan sebuah komputer, hanya saja tidak dilengkapi dengan monitor.

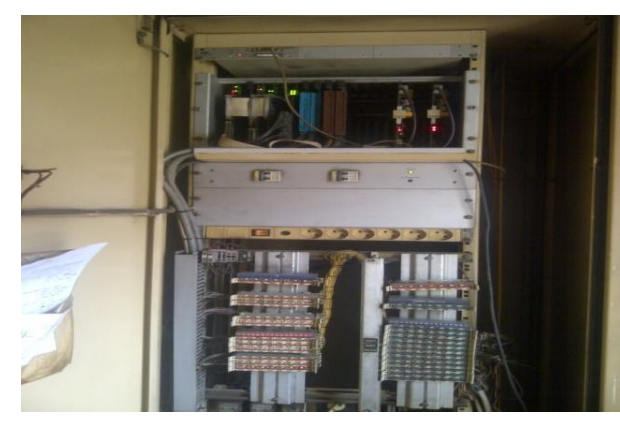

Gambar 13. RTU dengan Media Komunikasi Kabel Kontrol atau Radio

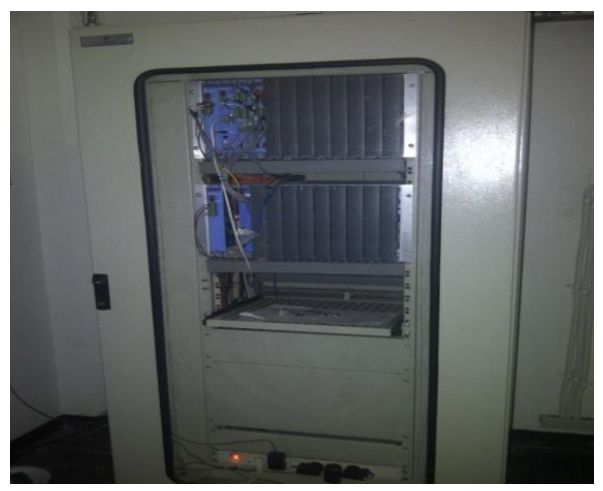

Gambar 14. RTU dengan Media Komunikasi Fiber optic

Pada prinsipnya RTU mempunyai fungsi utama sebagai berikut :

- Mendeteksi perubahan posisi saklar (Open/Close/Invalid).

- Mengetahui besaran tegangan, arus dan frekwensi (di Gardu Induk).

- Menerima perintah Remote Control dari Pusat Kontrol untuk membuka atau menutup.

- Mengirim data dan informasi ke Pusat Kontrol

Sesuai dengan perkembangan teknologi perangkat keras maupun perangkat lunak maka fungsi-fungsi suatu remote terminal unit pada saat ini telah ikut pula berkembang, misalnya sebagai:

1. Sebagai perangkat pemproses sinyal, RTU dirancang untuk dapat melakukan proses-proses sebagi perangkat pemroses pengiriman datadata kepusat pengendalian sistem seperti:

- Perubahan status peralatan gardu

- Perubahan besaran-besaran analog.

- Perubahan harga-harga Pulsa akumulator

- Pembaca besaran-besaran analog 
2. Memproses data-data perintah yang datang dari satu, dua atau tiga pusat kontrol, mengirim data-data jawaban/ hasil pengukuran/pemantauan ke pusat pengendalian yang sesuai dengan yang sudah ditetapkan (mampu berkomunikasi dengan satu, dua atau tiga pusat kontrol).

3. Sebagai Man Machine Interface (MMI), RTU harus dapat melakukan fungsi-fungsi sebagai berikut:

- Sebagai data logging, RTU berfungsi untuk merekam semua kejadian-kejadian, termasuk bila ada kelainan dari sistem maupun sinyal-sinyal yang sedang dipantau atau alarm. Data logging disini dapat bersifat pengarsipan. Laporan dapat diperoleh dari layar monitor atau dari printer, dalam bentuk kumpulan data berdasarkan tanggal/bulan sesuai yang diminta untuk keperluan pengecekan atau perbaikan.

- Event recording

Agak berbeda dengan data logging, disini direkam setiap kejadian sesuai dengan prosedur yang ada atau sesuai dengan yang diperintahkan/diprogram dari pusat pengendali, misalnya perintah buka/tutup pemutus hubungan beserta reaksinya (sudah dilaksanakan, gagal dsb), hasil-hasil pengukuran beserta komentarnya (nilai pengukuran atau berita khusus bila batas terlampaui, dsb).

4. Berkomunikasi dengan lokal personal komputer untuk keperluan supervisi dan pengendalian secara lokal dan untuk keperluan pemeliharaan.

Bila ditinjau dari sudut jaringan sistem pengendalian tenaga listrik maka remote terminal unit dapat berfungsi sebagai berikut:

1. Sebagai node atau terminal jaringan remote biasa.

Disini pusat-pusat pengendalian berhubungan langsung dengan RTU tersebut tanpa ada RTU perantara lain. Sistem hubungan ini efisien bila jarak antara gardu-gardu saling berjauhan letaknya, atau hampir sama jarak pusat pengendalian kemasing-masing gardu. Efisiensi pemanfaatan jalur komunikasi diperoleh dengan perancangan yang tepat dengan mempertimbangkan juga letak geografis gardu-gardu dan pusat pengendalian.

2. Sebagai RTU Concentrator

Concentrator biasanya diperlukan bila pada area tertentu terdapat lebih dari satu gardu-gardu yang letaknya tidak jauh. RTU-RTU yang berada digardugardu tersebut bertindak sebagai satelit dari RTU concentrator, mempooling data-datanya pada RTU concentrator, sehingga pusat pengendalian hanya perlu berkomunikasi dengan RTU concentrator saja. Ini bermanfaat untuk menghemat perangkat keras untuk jalur komunikasi, karena jarak terjauh biasanya antara pusat pengendalian dengan RTU concentrator, sedangkan jarak ke RTU-RTU satelit tidak begitu jauh. Pusat pengendalian meminta atau mengirim data-data/sinyal dari/ke RTU satelit pada RTU concentrator berdasarkan alamat-alamat RTU-RTU tersebut. RTU Concentrator juga bertindak sebagai RTU untuk lingkungan (gardu) dimana RTU itu berada karena RTU tersebut dilengkapi juga dengan modul-modul I/O.

3. Sebagai RTU SubMaster

RTU ini agak mirip dengan RTU Concentrator, tetap tanpa modulmodul I/O. Berguna untuk efisiensi jalur komunikasi untuk kondisi daerah yang pusat pengendalinya berjauhan letaknya dengan sekumpulan gardugardu, dan dilokasi tempat RTU SubMaster berada tidak diperlukan pengendalian/pemantauan peralatan listrik. Di RTU ini hanya diperlukan modul-modul untuk catu daya, CPU dan untuk komunikasi. Lebih berfungsi sebagai SubMaster daripada RTU Concentrator karena tidak mempunyai modul-modul I/O.

\section{METODE PENELITIAN}

Area Pengatur Distribusi Jakarta merupakan salah satu unit PT. PLN (Persero) Distribusi Jakarta Raya dan 
Tangerang yang berfungsi untuk mengatur dan mengendalikan jaringan tegangan listrik $20 \mathrm{KV}$ di wilayah Jakarta dan Tangerang. Pengendalian jaringan listrik tegangan menengah oleh Area Pengatur Distribusi (APD) berkoordinasi dengan PLN P3B, UPB CAWANG dan Sektor Jakarta dan Pulogadung yang mengendalikan sistem $500 \mathrm{KV}, 150 \mathrm{KV}$ dan $70 \mathrm{KV}$.

Dalam melaksanakan tugasnya APD dilengkapi dengan Sistem SCADA (Supervisory Control And Data Acquisition) dan Sistem Telekomunikasi, yang berfungsi sebagai sarana / alat yang membantu dispatcher di Pusat Kontrol dalam mengendalikan jaringan $20 \mathrm{KV}$ beserta peralatan switching yang ada di gardu induk, gardu hubung maupun gardu distribusi.

Pada gambar 16, pada penyulang $A$ terjadi suatu gangguan pada jaringan dimana gangguan tersebut terjadi pada jaringan Gardu Distribusi 3 arah bawah (setelah GD.3) sehingga GD.4 dan GD.5 padam. Dengan mengimplementasikan sistem SCADA, APD (Area Pengatur Distribusi) dapat melakukan manuver dari pusat kontrol dan tanpa harus datang ke GD.4 dan GD.5 untuk menghidupkan kembali listrik yang padam. Saat terjadi gangguan tersebut, muncullah gambar seperti gambar 16 pada layar computer.

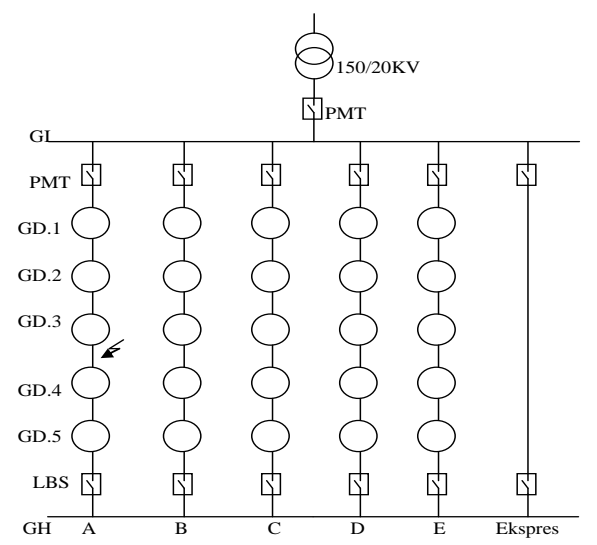

Gambar 16. Contoh Gangguan pada Jaringan Sistem Spindle

Lalu dispatcher melakukan manuver dengan membuka LBS (Load Break Switch) yang terdapat pada GD.3 arah bawah dan GD.4 arah atas dengan cara mengklik open pada layar komputer. Lalu komputer langsung mengirimkan sinyal ke RTU melalui media komunikasi, setelah itu RTU menerima sinyal untuk membuka LBS, maka RTU menyalakan motor yang ada didalam kubikel untuk membuka LBS. Setelah LBS terbuka, RTU kembali mengirimkan sinyal status bahwa LBS telah terbuka ke komputer melalui media komunikasi, maka pada layar komputer terbacalah status LBS open atau LBS terbuka. Dengan cara yang sama, dispatcher menutup LBS pada $\mathrm{GH}$ sehingga GD.4 dan GD.5 mendapat pasokan listrik dari Gardu Induk melalui penyulang ekspress. Dengan implementasi sistem SCADA ini APD dapat menghidupkan kembali listrik yang padam karna gangguan, tanpa harus menunggu gangguan tersebut selesai diperbaiki.

Contoh lain misalnya terjadi kenaikan beban pada penyulang $\mathrm{C}$ yang dikhawatirkan bila dibiarkan akan terjadi overload. Maka dispatcher harus melakukan manuver dengan membagi pasokan listrik menjadi dua yaitu arah atas dan arah bawah. Misalnya dispatcher membagi dengan cara GD.1 dan GD.2 mendapat pasokan listrik dari arah atas, sedangkan GD.3, GD.4, dan GD.5 mendapat pasokan listrik dari arah bawah. Dengan implementasi SCADA maka dengan mudah dispatcher menutup LBS pada $\mathrm{GH}$ untuk penyulang $\mathrm{C}$ sehingga GD.3, GD.4 dan GD.5 mendapat pasokan listrik dari $\mathrm{GH}$. Kemudian membuka LBS dari GD.2 arah bawah sehingga pasokan listrik dari arah atas hanya sampai ke GD.2. Dan kini telah terbagi pasokan listrik dengan cepat dan tanpa harus melakukan pemadaman.

Dengan mengimplementasikan sistem SCADA pengendalian listrik khususnya jaringan distribusi $20 \mathrm{KV}$ dapat dilakukan dari jarak jauh dan dengan waktu yang singkat.

\section{Indeks Keandalan SAIDI dan SAIFI}

Keandalan suatu komponen maupun sistem dalam arti luas dapat diartikan sebagai ukuran dari suatu performa, dimana suatu sistem dengan keandalan yang tinggi adalah suatu sistem dengan performa kerja yang baik. Namun untuk lebih spesifiknya, keandalan adalah kemampuan dari komponen ataupun 
sistem tersebut untuk dapat beroperasi dengan baik sesuai fungsinya pada periode waktu tertentu dan dengan persyaratan tertentu. Ada beberapa indeks keandalan yaitu SAIDI, SAIFI, CAIDI, ASAI dan ASUI. Namun dalam skripsi ini hanya dua indeks keandalan yang dibahas dalam analisa data mengenai implementasi sistem SCADA untuk pengendalian jaringan distribusi 20 KV di PT. PLN (Persero) Distribusi Jakarta Raya dan Tangerang, yaitu indeks SAIDI dan SAIFI.

SAIDI (System Average Interruption Duration Index) merupakan indeks yang menggambarkan durasi atau lama pemadaman rata-rata yang dialami pelanggan. Indeks ini dirumuskan dengan

$$
\text { SAIDI }=\frac{\text { Total lama padam }}{\text { Total jumlah pelang gan yang dilayani }}
$$

$S A I D I=\frac{\sum U_{i} N_{i}}{N_{i}}$

Dimana $U_{i}$ adalah durasi pemadaman untuk beban i, dan $\mathrm{N}$ adalah jumlah pelanggan pada titik beban i.

SAIFI (System Average Interruption Frequency Index) merupakan indeks yang menggambarkan frekuensi rata-rata pemadaman per pelanggan. Indeks ini dirumuskan dengan :

$$
\begin{aligned}
& \text { SAIFI }=\frac{\text { Total frekuensi padam }}{\text { Total jumlah pelanggan yang dilayani }} \\
& \ldots \ldots \ldots \ldots \ldots \ldots \ldots \ldots \ldots \ldots+(2) \\
& \text { SAIFI }=\frac{\sum \lambda_{i} N_{i}}{N_{i}}
\end{aligned}
$$

Dimana $\lambda_{i}$ adalah total frekuensi padam untuk beban i, dan $\mathrm{N}$ adalah jumlah pelanggan pada titik beban i.

\section{HASIL DAN PEMBAHASAN \\ 4.1. Data Gardu Distribusi}

Data didapatkan dari PT.PLN (Persero) Distribusi Jakarta Raya dan Tangerang. Data sebelum mengimplementasikan sistem SCADA diambil selama satu tahun dari tanggal 1 Oktober 2012 sampai 30 September 2013. Lalu pada bulan Oktober 2013 dipasanglah atau diimplementasikan sistem SCADA pada gardu-gardu distribusi tersebut. Untuk itu data setelah mengimplementasikan sistem SCADA diambil

\begin{tabular}{|c|c|c|c|c|c|c|c|c|}
\hline \multirow[b]{2}{*}{$\begin{array}{l}\text { Gardu } \\
\text { Distribusi }\end{array}$} & \multicolumn{4}{|c|}{$\begin{array}{l}\text { Sebelum Mengimplementasikan Sistem } \\
\text { SCADA }\end{array}$} & \multicolumn{4}{|c|}{ Setelah Mengimplementasikan Sistem SCADA } \\
\hline & $\begin{array}{c}\text { Lama } \\
\text { Padam } \\
\text { (menit) }\end{array}$ & $\begin{array}{c}\text { Frekuensi } \\
\begin{array}{c}\text { Padam } \\
\text { (kali) }\end{array}\end{array}$ & $\begin{array}{l}\text { SAIDI } \\
\text { (menit) }\end{array}$ & $\begin{array}{l}\text { SAIFI } \\
\text { (kali) }\end{array}$ & $\begin{array}{l}\text { Lama } \\
\text { Padam } \\
\text { (menit) }\end{array}$ & $\begin{array}{c}\text { Frekuensi } \\
\begin{array}{c}\text { Padam } \\
\text { (kali) }\end{array}\end{array}$ & $\begin{array}{l}\text { SAIDI } \\
\text { (menit) }\end{array}$ & $\begin{array}{l}\text { SAIFI } \\
\text { (kali) }\end{array}$ \\
\hline $\mathrm{CN} 42$ & 208 & 5 & 0.01296 & 0.00032 & 78 & 2 & 0.00486 & 0.00013 \\
\hline $\mathrm{CN} 48$ & 100 & 1 & 0.00623 & 0.00007 & 34 & 2 & 0.00212 & 0.00013 \\
\hline BT 152 & 177 & 2 & 0.01103 & 0.00013 & 37 & 1 & 0.00231 & 0.00007 \\
\hline TD 199 & 365 & 2 & 0.02273 & 0.00013 & 33 & 2 & 0.00206 & 0.00013 \\
\hline TD 61A & 101 & 1 & 0.00629 & 0.00007 & 112 & 3 & 0.00698 & 0.00019 \\
\hline $\mathrm{CN} 46$ & 151 & 1 & 0.00941 & 0.00007 & 34 & 2 & 0.00212 & 0.00013 \\
\hline CP 29F & 346 & 3 & 0.02155 & 0.00019 & 47 & 2 & 0.00293 & 0.00013 \\
\hline CP 219 & 454 & 5 & 0.02828 & 0.00032 & 277 & 6 & 0.01725 & 0.00038 \\
\hline PD 10 & 158 & 1 & 0.00984 & 0.00007 & 155 & 1 & 0.00966 & 0.00007 \\
\hline T 248 & 234 & 3 & 0.01458 & 0.00019 & 250 & 1 & 0.01557 & 0.00007 \\
\hline TD 91A & 1613 & 5 & 0.10045 & 0.00032 & 72 & 4 & 0.00449 & 0.00025 \\
\hline S 126 & 242 & 2 & 0.01507 & 0.00013 & 114 & 1 & 0.0071 & 0.00007 \\
\hline TOTAL & 4149 & 31 & 0.25842 & 0.00201 & 1243 & 27 & 0.07745 & 0.00175 \\
\hline
\end{tabular}
selama satu tahun mulai dari tanggal 1 November 2013 sampai 31 Oktober 2014.

Tabel 1. Data gardu distribusi sebelum dan sesudah mengimplementasikan system SCADA

Sumber : olahan data 


\subsection{Analisa Data}

Dari tabel 1 di atas, dapat dianalisa bahwa pada gardu distribusi CN 42 waktu lamanya padam pada saat setelah mengimplementasikan sistem SCADA jauh lebih cepat dibandingkan saat sebelum mengimplementasikan sistem SCADA, yaitu hemat waktu hingga $62,5 \%$ dari lamanya padam sebelum mengimplementasikan sistem SCADA, dan frekuensi padamnya pun jauh lebih sedikit. Pada gardu distribusi CN 48 lamanya padam saat setelah mengimplementasikan sistem SCADA juga jauh lebih cepat dibandingkan sebelum mengimplementasikan sistem SCADA. Walaupun saat setelah mengimplementasikan sistem SCADA terjadi dua kali padam dan sebelum mengimplementasikan sistem SCADA hanya satu kali padam dalam setahun, namun tetap jauh lebih cepat waktu padamnya pada saat setelah mengimplementasikan sistem SCADA pada gardu distribusi $\mathrm{CN} \mathrm{48,} \mathrm{yaitu} \mathrm{hemat}$ waktu hingga $64 \%$.

Kemudian pada gardu distribusi BT 152 lamanya padam saat setelah mengimplementasikan sistem SCADA jauh lebih cepat dari pada sebelum mengimplementasikan sistem SCADA, yaitu hemat waktu hingga $79,1 \%$ dan frekuensi padamnya juga lebih sedikit. Pada gardu distribusi TD 199 terjadi frekuensi padam yang sama yaitu dua kali, baik saat sebelum maupun setelah mengimplementasikan sistem SCADA. Namun lamanya padam jauh lebih cepat saat setelah mengimplementasikan sistem SCADA dari pada sebelum mengimplementasikan sistem SCADA, yaitu hemat waktu hingga 90,96\%.

Pada gardu distribusi TD 61A ternyata waktu lamanya padam lebih cepat dan frekuensi padamnya lebih sedikit saat sebelum mengimplementasikan sistem SCADA dari pada setelah mengimplementasikan sistem SCADA, namun demikian hanya sedikit perbedaan waktunya yaitu 11 menit atau $9,83 \%$ lebih cepat. Pada gardu distribusi CN 46 mengalami hal yang sama seperti gardu CN 48 yaitu walaupun saat setelah mengimplementasikan sistem SCADA terjadi dua kali padam dan sebelum mengimplementasikan sistem SCADA hanya satu kali padam dalam setahun, namun tetap jauh lebih cepat waktu padamnya pada saat setelah mengimplementasikan sistem SCADA pada gardu distribusi $\mathrm{CN} 46$, yaitu hemat waktu hingga $77,49 \%$.

Pada gardu distribusi CP $29 \mathrm{~F}$ lamanya padam jauh lebih cepat dan frekuensi padam lebih sedikit saat setelah mengimplementasikan sistem SCADA dari pada sebelum mengimplementasikan sistem SCADA yaitu hemat waktu hingga $86,42 \%$. Pada gardu distribusi CP 219 walaupun frekuensi padam lebih banyak pada saat setelah implementasi sistem SCADA, namun tetap jauh lebih cepat waktu padamnya dari pada sebelum mengimplementasikan sistem SCADA yaitu hemat waktu hingga $38,99 \%$.

Pada gardu distribusi PD 10 mengalami frekuensi padam yang sama yaitu satu kali dalam setahun, namun lamanya padam lebih cepat setelah mengimplementasikan sistem SCADA dari pada sebelum mengimplementasikan sistem SCADA, yaitu hemat waktu 1,9\%. Pada gardu distribusi T 248 ternyata lamanya padam lebih cepat pada saat sebelum mengimplementasikan sistem SCADA, namun demikian hanya sedikit perbedaan waktunya yaitu 16 menit atau $6,4 \%$ lebih cepat. Tetapi frekuensi padam lebih sedikit saat setelah mengimplementasikan sistem SCADA. Dan pada gardu distribusi TD 91A dan S 126 lamanya pada jauh lebih cepat dan frekuensi padam lebih sedikit saat setelah mengimplementasikan sistem SCADA dari pada sebelum mengimplementasikan sistem SCADA, yaitu berurutan hemat waktu hingga $95,53 \%$ dan $52,89 \%$.

Saat sebelum mengimplementasikan sistem SCADA yang padamnya lebih cepat hanya 2 gardu distribusi dari 12 gardu distribusi yang dianalisa, dan perbedaan waktunya pun hanyalah sedikit atau penghematan waktunya hanyalah di bawah 10\%. Sedangkan pada saat setelah mengimplementasikan sistem SCADA ternyata banyak terjadi penghematan waktu, yaitu sebanyak 10 gardu distribusi dari 12 gardu distribusi yang dianalisa. Dan penghematan waktu tersebut cukuplah besar, yaitu mulai dari $1,9 \%$ hingga $95,53 \%$. 
Dengan demikian dapat dianalisa bahwa dari 12 gardu distribusi, ada 10 gardu distribusi yang memiliki indeks keandalan SAIDI jauh lebih baik saat setelah mengimplementasikan sistem SCADA dibandingkan sebelum mengimplementasikan sistem SCADA. Dan juga dari 12 gardu distribusi, ada 6 gardu distribusi yang memiliki indeks keandalan SAIFI lebih baik saat setelah mengimplementasikan sistem SCADA, 4 gardu distribusi yang memiliki SAIFI lebih baik saat sebelum mengimplementasikan sistem SCADA, dan 2 gardu distribusi memiliki SAIFI yang sama baik saat sebelum maupun setelah mengimplementasikan sistem SCADA.

Dan jika dilihat secara total lamanya padam dan frekuensi padam pada saat sebelum dengan setelah mengimplementasikan sistem SCADA, dapat dianalisa bahwa setelah mengimplementasikan sistem SCADA terjadi penghematan waktu sebesar 2906 menit atau 48,44 jam, dan frekuensi padamnya 4 kali lebih sedikit dibandingkan dengan sebelum mengimplementasikan sistem SCADA. Ini artinya indeks keandalan SAIDI dan SAIFI jauh lebih baik pada saat setelah mengimplementasikan sistem SCADA.

\section{KESIMPULAN}

1. Dengan mengimplementasikan sistem SCADA, PT.PLN (Persero) Distribusi Jakarta Raya dan Tangerang bisa mendapatkan penghematan waktu lamanya padam yang cukup besar yaitu mulai dari 1,9\% sampai $95,53 \%$, dan juga dapat menekan frekuensi terjadinya padam.

2. Setelah mengimplementasikan sistem SCADA terjadi penghematan waktu sebesar 2906 menit atau 48,44 jam, dan frekuensi padamnya 4 kali lebih sedikit dibandingkan dengan sebelum mengimplementasikan sistem SCADA. Ini artinya indeks keandalan SAIDI dan SAIFI jauh lebih baik pada saat setelah mengimplementasikan sistem SCADA.

\section{REFERENSI}

Basri, Hasan. 1997. Sistem Distribusi Daya Listrik. Jakarta : ISTN.

Cucuk, Agustinus. 2014. Diktat Sistem SCADA. Jakarta : PT PLN DISJAYA.

Communication Technologies, 2004, NCS TIB 04-1, Supervisory Control and Data Acquisition (SCADA) System, Virginia, Oktober

David Bailey \& Erwin Wright. 2003, Practical SCADA for Industry. Newnes of Elsevier. Massachussets.

Gordon Clarke \& Deon Reynders. 2004, Practical Modern SCADA Protocols: DNP3, 60870.5 and Related Systems. Massachussets.

Keith Strouffer et al, 2006, Guide to Supervisory Control and Data Acquistion (SCADA) and Industrial Control Systems Security, National Institute of Standards and Technology, September

Lester Abbey, 2003, Evolution of SCADA Systems, SCADA Conference, 28-29 October, Auckland

Pandjaitan, Bonar. 1999. Teknologi Sistem Pengendalian Tenaga Listrik Berbasis SCADA. Jakarta : Prenhallindo. 